Original article

\title{
A spatial scale assessment of habitat effects on arthropod communities of an oceanic island
}

\author{
Pedro Cardoso $^{\text {a, } *}$, Silvia C. Aranda ${ }^{\text {a,b }}$, Jorge M. Lobo ${ }^{b}$, Francisco Dinis ${ }^{\text {a }}$, Clara Gaspar ${ }^{\text {, }}$ Paulo A.V. Borges ${ }^{\text {a }}$ \\ ${ }^{a}$ CITA-A (Azorean Biodiversity Group), Department of Agricultural Sciences, University of Azores, 9701-851 Angra do Heroísmo, Portugal \\ ${ }^{\mathrm{b}}$ Departamento de Biodiversidad y Biología Evolutiva, Museo Nacional de Ciencias Naturales (CSIC), Madrid, Spain
}

\section{A R T I C L E I N F O}

\section{Article history:}

Received 23 January 2009

Accepted 14 May 2009

Published online 4 June 2009

\section{Keywords:}

Connectivity

Dispersal

Endemic species

Exotic plantations

Habitat heterogeneity

Introduced species

Land-use

Landscape matrix

Macaronesia

Native species

\begin{abstract}
A B S T R A C T
Most habitats in the Azores have undergone substantial land-use changes and anthropogenic disturbance during the last six centuries. In this study we assessed how the richness, abundance and composition of arthropod communities change with: (1) habitat type and (2) the surrounding land-use at different spatial scales. The research was conducted in Terceira Island, Azores. In eighty-one sites of four different habitat types (natural and exotic forests, semi-natural and intensively managed pastures), epigaeic arthropods were captured with pitfall traps and classified as endemic, native or introduced. The land-use surrounding each site was characterized within a radius ranging from 100 to $5000 \mathrm{~m}$. Nonparametric tests were used to identify differences in species richness, abundance and composition between habitat types at different spatial scales. Endemic and native species were more abundant in natural forests, while introduced species were more abundant in intensively managed pastures. Natural forests and intensively managed pastures influenced arthropod species richness and composition at all spatial scales. Exotic forests and semi-natural pastures, however, influenced the composition of arthropod communities at larger scales, promoting the connectivity of endemic and native species populations. Local species richness, abundance and composition of arthropod communities are mostly determined by the presence of nearby natural forests and/or intensively managed pastures. However, semi-natural pastures and exotic forests seem to play an important role as corridors between natural forests for both endemic and native species. Furthermore, exotic forests may serve as a refuge for some native species.
\end{abstract}

(c) 2009 Elsevier Masson SAS. All rights reserved.

\section{Introduction}

Habitat loss and disturbance of natural landscapes due to human action have been implicated as the main causes of the current global biodiversity decline (Didham et al., 1998, 2007; Parker and Nally, 2002; Hoekstra et al., 2005). Such modification of natural habitats generally increases the landscape heterogeneity, resulting in a mosaic of patches in which both natural, semi-natural and exotic habitat types are more or less interconnected (Malanson and Cramer, 1999; Ricketts, 2001; Fischer and Lindenmayer, 2007). Adjacent patches of different habitats create edge effects and an opportunity for extinction-proneness of disturbance sensitive species (Didham et al., 1998). This mosaic of habitat types may change the spatial dynamics of species at the regional scale and

\footnotetext{
* Corresponding author. Smithsonian Institution, National Museum of Natural History, PO Box 37012, MRC 105, Room E-509, Washington, DC 20013-7012, USA. Tel.: +1 202633 0661; fax: +1 2027863141 .

E-mail address: pcardoso@ennor.org (P. Cardoso).
}

consequently their regional and local scale distribution and abundance (Ricklefs, 2008). In oceanic islands, which have often been free from human influence until recently, this may mean the spread of exotic species putting endemic and native species at risk (Borges et al., 2006). The study of species richness, abundance and composition changes across habitat types, as well as of habitat connectivity, is crucial for understanding current local diversity and promoting adequate conservation management strategies (Williamson, 1996; Olden, 2006). Therefore, it is critical to understand which habitat types are required to support populations of endemic and threatened taxa of high value for conservation of local biodiversity.

The Azorean archipelago, which was mostly covered by Laurisilva forest prior to human settlement, has undergone drastic land-use changes since the first inhabitants arrived almost 600 years ago. The islands are currently characterized by a dominance of non-native habitat types: intensively managed pastures for cattle; arable land with several types of crops (e.g., corn, potatoes, tea, orchards, etc.); large uniform forests of exotic species; abandoned crop fields and pastures covered with exotic invasive plants 
(e.g. Pittosporum undulatum); semi-natural high-altitude pastures. Protecting pristine forests is considered to be one of the most common and effective conservation strategies worldwide, but it is a particularly challenging task in this archipelago since the original Azorean forests are now restricted to a few high-altitude fragments (see Borges et al., 2005, 2006). The fragments, varying in size from 4 to $1000 \mathrm{ha}$, are often disturbed by the invasion of introduced species (Silva and Smith, 2004; Borges et al., 2006). This disturbance is also reflected in the varying values of biotic integrity that arthropod communities across natural forest fragments present (Cardoso et al., 2007).

Local diversity is determined not only by local conditions, but also by the regional species pool, which in turn depends on regional environmental conditions and historical factors (Ricklefs, 1987, 2008; Borges and Brown, 2004; He et al., 2005). This regional species pool affects the probability of immigration of individuals from neighbouring localities, which depends on the degree of isolation of each locality as well as on the dispersal ability of focal species (Wiens, 1989; Batáry et al., 2007). Hence, local diversity depends on the land-use surrounding each site, and more distant patches with similar habitat qualities are less likely to act as sources of dispersal (Stephens and Krebs, 1986; Hanski, 1999). These arguments and others highlight the widely recognized view that spatial scale is of vital importance for understanding ecological patterns and processes (Whittaker et al., 2001; Rahbek, 2005; Turner and Tjørve, 2005).

The spatial scale dependence of species richness or abundance can be analysed using a multiple scale approach (Pearman, 2002). In arthropods (see Chust et al., 2004; Holland et al., 2004; Clough et al., 2005; Gaucherel et al., 2007; González-Mejias et al., 2007; Hendrickx et al., 2007; Driscoll, 2008), such analysis can help to identify the spatial scales at which a predictor variable influences species richness and abundance of local communities.

Our study addresses how spatial scale affects the relationship between the habitat and diversity of local arthropod communities on an oceanic island (Terceira Island, archipelago of the Azores) that has been subject to a relatively recent but intense process of anthropogenic disturbance. Using a sampling of local arthropod communities across the four main habitat types present on Terceira Island, which differ in both their arboreal cover (forest vs. pastures) and origin (natural vs. exotic), the aims of this study were to understand how richness, abundance and composition of endemic, native and introduced arthropod communities change with: (1) habitat type and (2) the surrounding land-use at different spatial scales. We tested if, as expected, habitat type and land-use structure do not greatly affect the diversity of introduced species, due to their supposedly higher dispersal ability and their aptitude to be adapted to a wider range of environmental conditions. On the contrary, and according to the evolutionary species pool hypothesis (Pither and Aarssen, 2005), endemic and native species should colonize and survive on more environmentally specialized conditions, being therefore also more deeply influenced by the landscape structure of historically favourable and common habitats. Thus, we expected that endemic and native species respond more negatively to matrix heterogeneity than exotic species.

\section{Materials and methods}

\subsection{Study area}

The Azorean archipelago is located in the North Atlantic Ocean, roughly between the coordinates $37-40^{\circ} \mathrm{N}$ latitude and $25-31^{\circ} \mathrm{W}$ longitude. It is composed of nine main islands and some small islets aligned on a WNW-ESE course and is fully oceanic, that is, made up of volcanic islands of recent origin (the oldest island, S.Maria, being
8.12 Myr B P). Terceira Island (Fig. 1), with an area of c. $402 \mathrm{~km}^{2}$ and maximum elevation of $1021 \mathrm{~m}$, is comprised of four main volcanic mountain ranges (Serra de Santa Bárbara, Serra do Morião, Pico Alto and Serra do Cume). The climate is temperate oceanic, i.e., strongly influenced by the proximity of the ocean and by the island topography, which produces high levels of relative atmospheric humidity, especially in the native, high altitude, semi-tropical, evergreen laurel forest (Laurisilva). The temperate oceanic climate is also characterized by little temperature fluctuation throughout the year. The natural Laurisilva forest is characterized by reduced tree stature (usually up to $5 \mathrm{~m}$, rarely reaching $10 \mathrm{~m}$ ), shallow soil and rugged terrain.

For the current investigation, we used a gradient of human induced land-use changes in Terceira (Fig. 1). The map was generated using aerial photography and fieldwork. A detailed spatial distribution of exotic forest was obtained from the Azorean Forest Services. From these sources, we discriminated the following four habitat types, which comprise around $87 \%$ of the total island area: natural forests, exotic forests (Eucalyptus spp. and Cryptomeria japonica), semi-natural pastures and intensively managed pastures.

\subsection{Site selection}

Eighty-one sites were sampled (Fig. 1): 45 in natural forests, 9 in exotic forests, 11 in semi-natural pastures and 16 in intensively managed pastures. Fifty-six percent of the sampling sites were in natural forests, which occupy around $9 \%$ of the total island area, while only $20 \%$ of the sampling sites were in intensively managed pastures, which are the most widely distributed habitat type, representing almost $48 \%$ of the total island area. The number of sampling sites for the other two habitat types was relatively proportional to the amount of the island that each habitat covers: $11 \%$ and $14 \%$ of sampling sites were exotic forests and semi-natural pastures respectively, each of which occupies around 15\% of the island's area. The sampling was intentionally biased towards the habitats in which we knew that higher number of endemic species and higher beta diversity occurred (natural forests). We tried to spread the sampling sites all over the island independently of the surrounding land-use matrix, although intensively managed pastures tend to be located in peripheral low-altitude areas, while natural forests tend to be present only in central high-altitude areas (see Fig. 1).

\subsection{Sampling procedures}

At each site, epigaeic soil fauna were captured along $150 \mathrm{~m}$ long transects. Thirty pitfall traps, plastic cups with a top diameter of $42 \mathrm{~mm}$ and $78 \mathrm{~mm}$ deep, were dug into the soil so that the rim of the cup was level with the surface. Half of the traps were filled with approximately $60 \mathrm{ml}$ of diluted ethylene glycol (anti-freeze liquid) and the other half with the same volume of a general attractive solution (Turquin), which was made of dark beer and some preservatives ( $10 \mathrm{~g}$ chloral hydrate $+5 \mathrm{ml}$ formalin $+5 \mathrm{ml}$ acetic acid for $1 \mathrm{~L}$ of beer; see Turquin, 1973). Traps were spaced $5 \mathrm{~m}$ from one another, alternating Turquin and ethylene glycol traps, and were left in the field for two weeks in the summers of different years (see Borges et al., 2005 for a complete description). The majority of arthropods were identified at the species level or, when this was not possible, morphospecies. All species were classified as endemic, native or introduced. Endemic species are those that occur only in the Azores as the result of either speciation events (neoendemics) or extinction of the populations in other places (palaeoendemics). Native non-endemic species arrived by longdistance dispersal to the Azores, cannot be associated with human activities (intentional or accidental human introduction) and are 


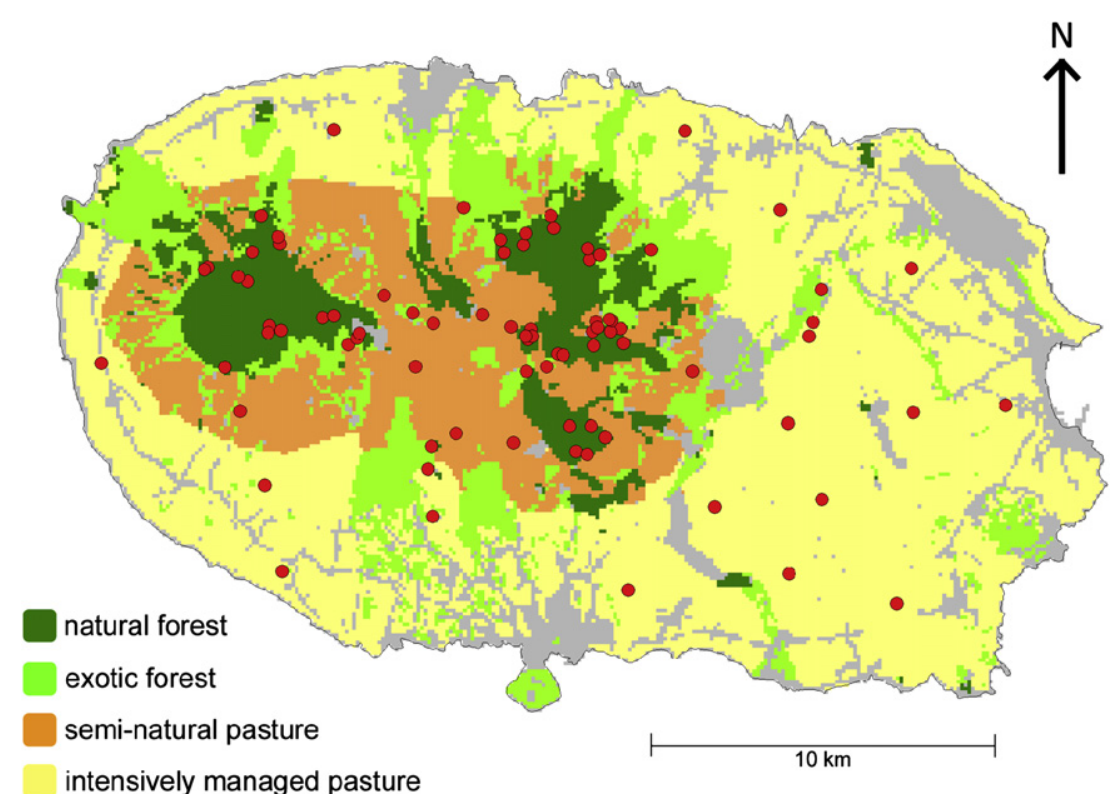

Fig. 1. Distribution of the four studied habitat types on Terceira Island. Dots represent the 81 sampling sites.

also known from other regions. Introduced species are those believed to have arrived in the archipelago due to human activities and often have a cosmopolitan distribution. When it was not possible to obtain a correct species identification, the colonisation status was determined using the following criteria: endemic if it belonged to a genus composed of only endemic taxa in the archipelago; introduced if it belonged to a family mainly composed of exotic species in the archipelago (e.g. Tortricidae, Nitidulidae); native in all cases for which there was no reliable data. The sampling unit considered for this study was individual sampling sites (set of 30 pitfall traps).

\subsection{Sampling effort analysis}

Richness comparisons of areas must always be analysed with certain cautions; namely, the sampling completeness of the sites should not be different. We first calculated each site's estimated richness with the Chao1 estimator (Chao, 1984) and calculated completeness as the observed to estimated richness ratio. However, the Chao estimates were far from reliable, and the completeness variance of the different sites belonging to each habitat was very large (results not shown). The completeness values were therefore unreliable.

As an alternative to completeness, we have calculated the sampling intensity for each site, defined as the specimens to species ratio, a crude measure of sampling effort (Cardoso et al., 2008a,b). Additionally, we have estimated the final slopes of overall species richness accumulation curves for all sites. All curves were samplebased and rescaled to individuals as suggested by Gotelli and Colwell (2001). The final slopes of curves were calculated as in Cardoso et al. (2008a,b):

Slope $=1 /\left(n_{S}-n_{S-1}\right)$

where $n_{S}=$ final number of individuals for each curve (corresponding to the total richness value $S$ ) and $n_{S-1}=$ number of individuals corresponding to the point in the curve where the final single species was added (corresponding to a richness value of $S$ - 1) (Cardoso et al., 2008a,b). The sampling intensity and slopes were both different between pasture and forest habitats, pastures presenting statistically significantly higher intensities
(Mann-Whitney $p<0.011$ in all paired comparisons) and lower slopes (Mann-Whitney $p<0.037$ in all paired comparisons) than forests.

As direct comparisons of richness and abundance between habitats were compromised by different sampling intensities, we have tested if the percentages of endemic, native and introduced species were as prone to change with sampling effort as their richness. Java-coded software was generated to randomize species accumulation curves of all species groups and respective percentages for all sites (we used 1000 randomizations; code available from the first author by request). Contrary to absolute values, relative values (percentages) mostly did not change or rapidly reached the asymptote with increasing sampling efforts (see Appendix S1). These results demonstrated that different habitats should be compared with percentages of endemic, native and introduced species instead of their absolute values. However, and since we found that absolute values follow the same trend as relative values, although usually with less significant probabilities, we have also included them in the analyses to increase the robustness of our conclusions.

\subsection{Data analysis}

We performed several tests for a previous evaluation of differences between habitat types. In particular, we examined the effects of arboreal cover (forest vs. pasture) and habitat origin (natural/ semi-natural vs. exotic/intensive) on species richness, abundance and composition. Non-parametric Kruskal-Wallis ANOVA (by ranks) tests and Mann-Whitney $U$ tests were used to scrutinize differences in species richness and abundance data. An analysis of similarities (ANOSIM) was used to examine between-habitat compositional differences (Clarke and Warwick, 2001). The compositional dissimilarity between all pairwise site comparisons was calculated using the recommended Bray-Curtis index (Clarke and Warwick, 2001) with the $\log (x+1)$ of the species abundances. PRIMER v5 software was used for these computations (Clarke and Gorley, 2001).

Subsequently, we determined habitat influence according to spatial scale by a simple multiple scale approach similar to the one followed in other studies (Steffan-Dewenter et al., 2002; Schmidt 
et al., 2008). The four habitat types' areas around each of the 81 sampling sites were analysed at ten scales, 100, 200, 400, 600, 800, 1000, 2000, 3000, 4000 and 5000 m, using the Idrisi Kilimanjaro GIS software (Clark Labs, 2004). Thus, a high percentage area of the habitat of a site at the scale considered implied that this site was surrounded by similar habitat conditions, resulting in higher connectivity and lower edge effects (Debinski and Holt, 2000; Damschen et al., 2006). We then calculated the Spearman rank correlation coefficient values between the species richness/abundance of endemic, native and introduced species at each site and the area corresponding to each of the four habitat types, repeating the calculation for the ten different scales.

\subsection{Assumptions and conceptual proposal}

We define local and regional effects as those affecting a habitat at narrow or wide scales. We assume that local diversity is affected differentially by several processes at different scales, so demographic factors such as birth and death rates would be the main forces responsible for population size at local scales, while emigration and immigration (i.e., dispersal) processes would be more relevant at regional scales (see Thomas and Kunin, 1999). Thus, our definition of local and regional effects also implies a differential role of the forces able to explain the presence of an individual in a locality. This assumption is supported by empirical and theoretical studies (Debinski and Holt, 2000; Trani, 2002; Leibold et al., 2004). We also assume that the effect of a process is expected to be higher at one scale if it operates effectively (Boyce, 2006). Thus, if the significance of a predictor increases drastically when changing from one scale to the next, it is likely that the processes represented by this predictor begin to manifest in the latter scale. This scale effect is also well supported (Dungan et al., 2002). Hence, from a conceptual point of view, the formerly mentioned correlation analyses can generate four main patterns, illustrated in Fig. 2 with hypothetical species richness values as an example. In pattern $A$, the larger the area of a habitat, the larger the number of species at any scale; alternatively, in pattern $B$, the larger the area of a habitat, the fewer species at any scale. These two patterns are scale-independent, so habitat area always has

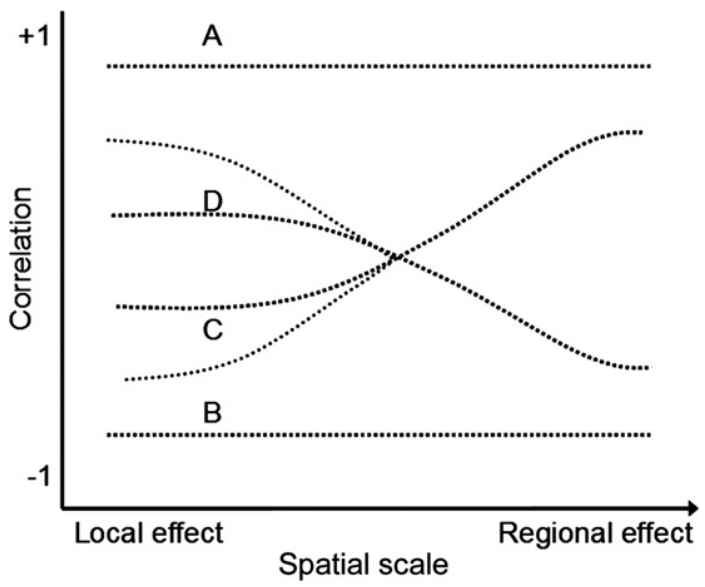

Fig. 2. Schematic representation of four possible patterns of correlation variation between species richness and habitat area across scales. In pattern $A$, the larger the habitat area, the larger the number of species at any scale; alternatively, in pattern B, a larger habitat area implies a smaller number of species. In these two scale-independent patterns, habitat area always has a favourable or unfavourable local and regional effect. In patterns $C$ and $D$, correlations between habitat area and species richness increase or decrease with the scale due to positive or negative regional effects. The different broken lines at local scales for patterns $C$ and $D$ approximate the cases in which significant correlations can or cannot be obtained. a favourable or an unfavourable effect in which local and regional dynamics would be interconnected (Resetarits, 2005). Herein, we denote favourable and unfavourable habitat types as those that follow patterns A and B, respectively. However, the correlation between area of habitat and species richness can increase (pattern C) or decrease (pattern $\mathrm{D}$ ) depending on the scale due to positive or negative regional effects (Fig. 2). A habitat can have a positive regional effect on local diversity by increasing the connectivity among local populations and a negative effect by acting as a barrier to population interchange. Herein, we denote as connector and insulator habitat types those that respectively follow the scaledependent patterns $C$ and $D$.

\section{Results}

A total of 35,217 arthropod specimens were identified to the species, or in some cases, to the morphospecies level. Of the 263 epigean arthropod species identified, 40 were considered to be Azorean endemics, 95 native to the islands (excluding endemics) and 128 introduced (Table 1).

\subsection{Between-habitat differences}

Richness, abundance and respective proportions were significantly different ( $p<0.002$ in all cases) for all groups of species (endemics, natives and introduced) between habitats of different arboreal covers (forests vs. pastures) and origins (natural/seminatural vs. exotic/intensive). The exception was the absolute abundance of endemics, which was not different between arboreal cover types or habitat origins ( $p>0.278$ in both cases). The numbers of endemic and native species or individuals were higher in forests and (semi-)natural habitat types, and the numbers of introduced species or individuals were higher in pastures and exotic habitat types. Furthermore, the three groups of species showed statistically significant between-habitat differences in species richness (Kruskal-Wallis test; endemics: $H=36.1$, $p<0.001$; natives: $H=10.7, p=0.013$; introduced: $H=51.8, p$ $<0.001$ ), abundance (Kruskal-Wallis test; natives: $H=17.8$, $p<0.001$; introduced: $H=37.4, p<0.001$ ), proportion of species richness (Kruskal-Wallis test; endemics: $H=56.6, p<0.001$; natives: $H=32.5, p<0.001$; introduced: $H=54.0, p<0.001)$ and proportion of individuals (endemics: $H=19.7, p<0.001$; natives: $H=39.6, p<0.001$; introduced: $H=39.7, p<0.001)$. Once again, the only exception was the absolute abundance of endemic species (Kruskal-Wallis test; $H=6.3, p=0.097$ ). However, only certain post hoc pairwise comparisons were significant (Fig. 3). Natural forest sites harboured a significantly higher richness of endemic species and proportion of endemic species and individuals than all the remaining habitat types. Natural and exotic forests contained higher values of native species than intensive pastures and even semi-natural pastures in the case of proportions. Finally, pastures had higher values of introduced species and individuals than both forest types, with natural forests presenting the lowest numbers.

The composition of arthropod communities was statistically different among the four studied habitat types for all species groups (ANOSIM; $R=0.715, p<0.001$ for endemic species; $R=0.732$, $p<0.001$ for native species; and $R=0.715, p<0.001$ for introduced species). All pairwise tests were also significant, except for endemic species composition in exotic forests vs. semi-natural pastures (ANOSIM; $R=0.0043, p=0.189$ ).

\subsection{Spatial dependence}

Local (site) species richness was influenced differentially by habitat type at different spatial scales (Fig. 4). Endemic species were 
Table 1

Orders identified in this study with counts of endemic, native and introduced species.

\begin{tabular}{|c|c|c|c|c|c|c|c|c|}
\hline \multirow[t]{2}{*}{ Order } & \multicolumn{4}{|l|}{ Richness } & \multicolumn{4}{|c|}{ Abundance } \\
\hline & Endemic & Native & Introduced & Total & Endemic & Native & Introduced & Total \\
\hline Araneae & 10 & 7 & 29 & 46 & 1476 & 1237 & 16,324 & 19,037 \\
\hline Blattaria & 0 & 1 & 0 & 1 & 0 & 27 & 0 & 27 \\
\hline Chilopoda & 0 & 6 & 1 & 7 & 0 & 2657 & 16 & 2673 \\
\hline Coleoptera & 14 & 28 & 68 & 110 & 1415 & 740 & 3838 & 5993 \\
\hline Dermaptera & 0 & 0 & 2 & 2 & 0 & 0 & 218 & 218 \\
\hline Diplopoda & 0 & 4 & 5 & 9 & 0 & 299 & 1707 & 2006 \\
\hline Hemiptera & 5 & 24 & 9 & 38 & 265 & 502 & 184 & 951 \\
\hline Lepidoptera & 8 & 12 & 10 & 30 & 351 & 458 & 559 & 1368 \\
\hline Microcoryphia & 1 & 0 & 0 & 1 & 15 & 0 & 0 & 15 \\
\hline Neuroptera & 1 & 0 & 0 & 1 & 2 & 0 & 0 & 2 \\
\hline Opiliones & 0 & 2 & 0 & 2 & 0 & 2337 & 0 & 2337 \\
\hline Orthoptera & 0 & 0 & 2 & 2 & 0 & 0 & 258 & 258 \\
\hline Pseudoscorpiones & 0 & 2 & 0 & 2 & 0 & 271 & 0 & 271 \\
\hline Psocoptera & 0 & 5 & 0 & 5 & 0 & 10 & 0 & 10 \\
\hline Symphyla & 0 & 1 & 0 & 1 & 0 & 1 & 0 & 1 \\
\hline Thysanoptera & 0 & 3 & 2 & 5 & 0 & 10 & 25 & 35 \\
\hline Trichoptera & 1 & 0 & 0 & 1 & 15 & 0 & 0 & 15 \\
\hline Total & 40 & 95 & 128 & 263 & 3539 & 8549 & 23,129 & 35,217 \\
\hline
\end{tabular}

always positively correlated with the area of natural forest available at any of the considered scales. The correlation values of this habitat were always greater than those of any other habitat. Local endemic species were also significantly and positively correlated with the area of exotic forest or semi-natural pastures, but only when the area of these habitat types was estimated at distances greater than $2000 \mathrm{~m}$ (scale $\geq 2000 \mathrm{~m}$ ). Intensively managed pastures always presented a negative correlation with local endemic species values,
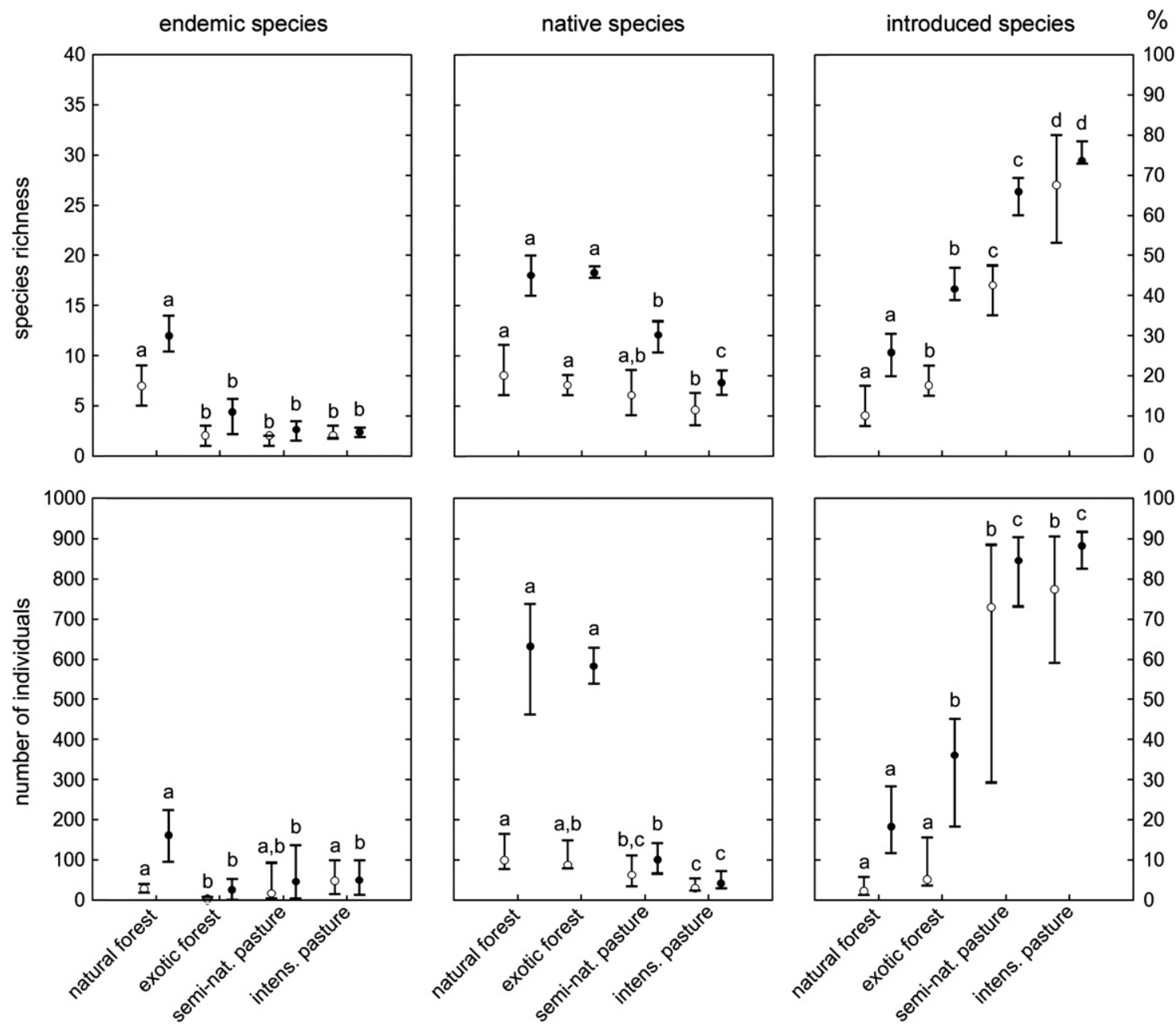

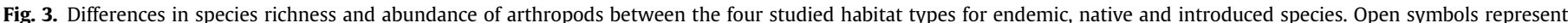

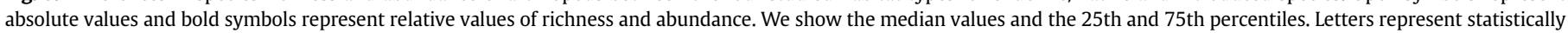
different groups of habitat types as determined by a Mann-Whitney $U$ test for all paired comparisons. 
regardless of the scale considered. Once more, for the absolute values of endemic species abundances, almost all the correlations lose significance.

A very similar correlation pattern was found for native species (Fig. 4). Local species richness was positively correlated with the area of natural forest at all scales, but only from $400 \mathrm{~m}$ and above for semi-natural pastures and exotic forests. Intensively managed pastures were always negatively correlated with native species values. The patterns for native species abundance were mostly similar (Fig. 4).

The pattern for introduced species was very different (Fig. 4). Both local species richness and abundance were negatively correlated with natural forest area and positively correlated with intensively managed pasture area at all the considered scales, these two habitat types having the highest correlation values. Exotic forests and semi-natural pastures were negatively and significantly correlated with introduced species values when the scale was above $400-2000 \mathrm{~m}$.

\section{Discussion}

Our results demonstrate that local arthropod diversity was influenced both by local and regional processes (Borges and Brown, 2004; Chust et al., 2004; Holland et al., 2004; Gaucherel et al., 2007; González-Mejias et al., 2007; Driscoll, 2008; Ricklefs, 2008). This suggests that either the mechanisms controlling species diversity or their intensity vary with the spatial scale (Wiens, 1989). Although many contradictory results exist, arthropods seem to be a group for which fragmentation, corridors, edge effects and habitat modification greatly affect species richness, abundance and composition (Didham et al., 1998, 2007; Debinski and Holt, 2000; Ewers and Didham, 2008; Heleno et al., 2009). We suggest that the discrimination of species groups by different degrees of adaptation to natural habitat types in a territory can help to further distinguish the roles of local and regional processes. This is because different species can use space in different ways, but species groups defined according to their adaptation to the natural habitat types share similar spatial patterns.

As expected, natural forest was a favourable habitat for indigenous taxa, i.e. endemic and native species. This reveals the negative effect of transforming natural forest into intensively managed pastures, not only by making the local survival of many endemic and native species impossible, but also by severing the connections among local communities. Native and mainly endemic species are favoured by the increases in area and connectivity (see Damschen et al., 2006) of the natural habitat that occupied most of Terceira Island before the beginning of human land-use changes.

Both semi-natural pastures and exotic forests seemed to act as connectors for endemic and native species at large spatial sales. However, these results need to be analyzed with caution. In fact, endemic species
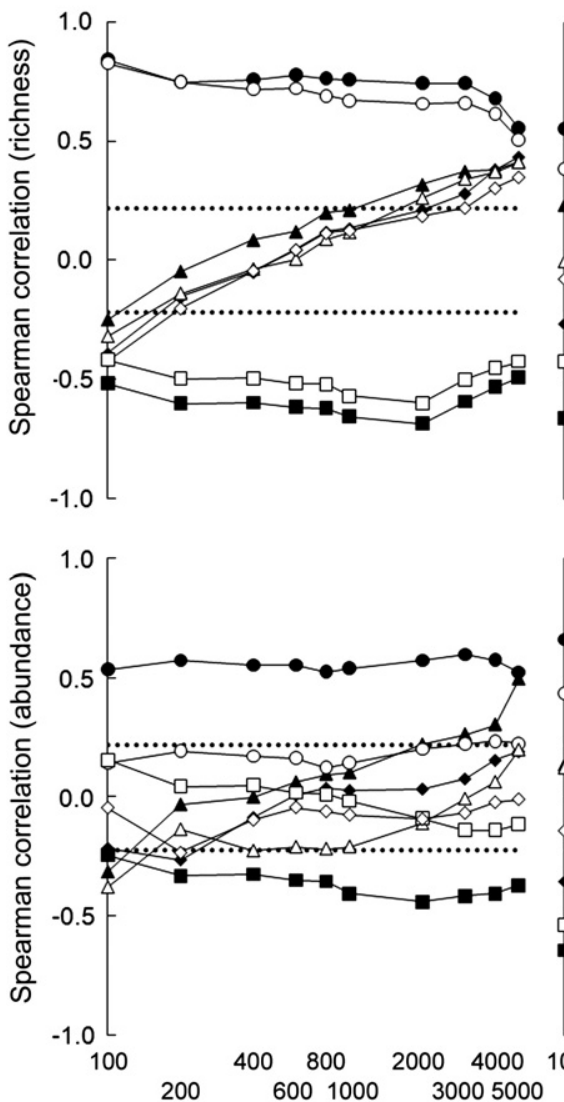
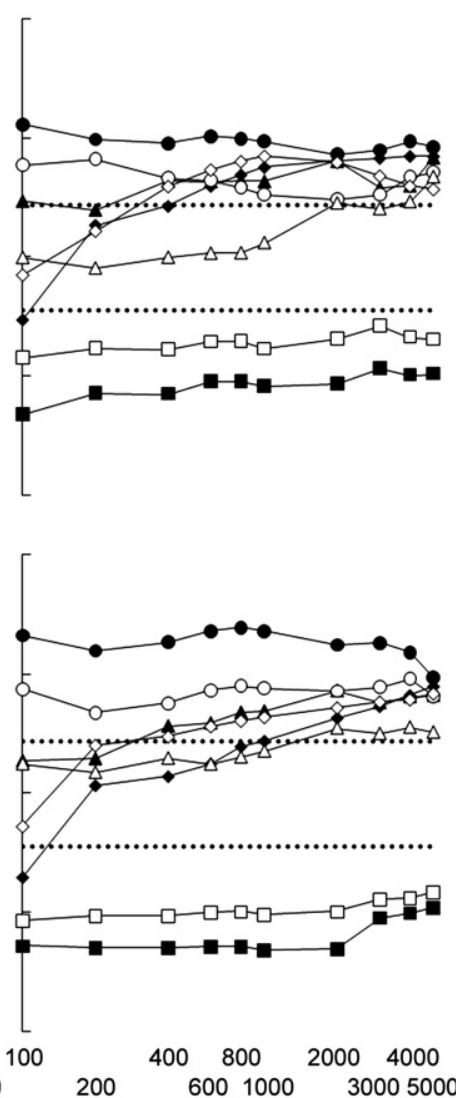

native species
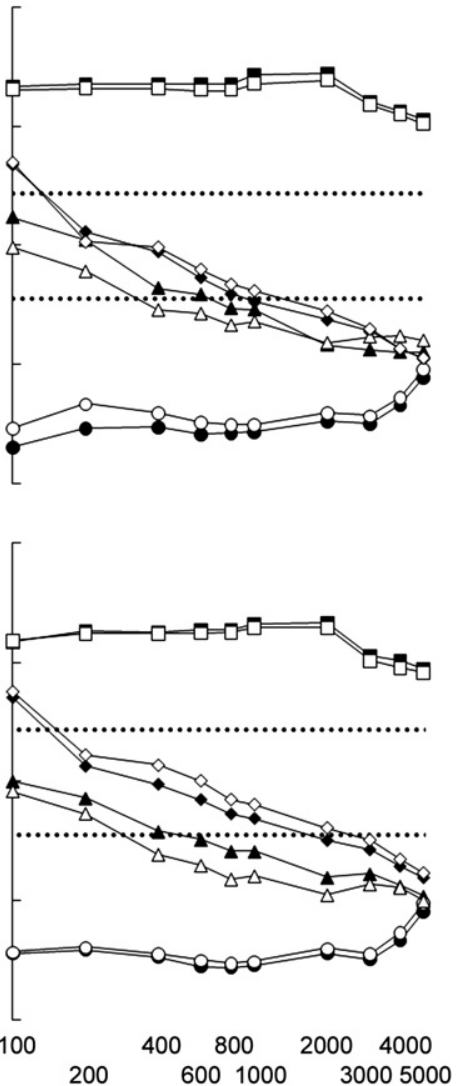

spatial scale $(\mathrm{m})$

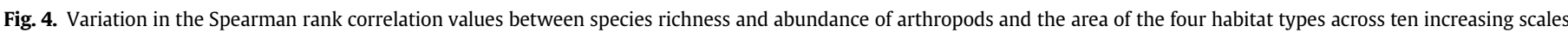

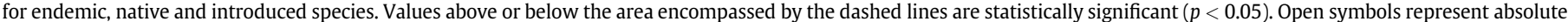

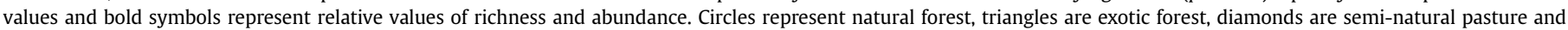
squares represent intensively managed pastures. 
due to the small area of natural forest and the spatial structures of the different habitat types present on the island, which are arranged in a concentric fashion (see Fig. 1), habitat heterogeneity inevitably increases at large scales due to the appearance of other habitat types. Our results imply that in such circumstances, some endemic and native species could survive if the disappearing natural forest is replaced with exotic forest or semi-natural pastures instead of intensively managed ones. Indeed, elsewhere, traditionally managed semi-natural pastures are also recognized for their value in conserving native species (e.g. Woodcock et al., 2007). The correlation values also supported this point of view. For endemic species, all positive correlations at the larger scale were the smallest, suggesting that the decrease in natural forest area and the increase in edge effects at larger scales negatively affected the endemic richness of arthropod communities (see also Ewers and Didham, 2008). In the case of native species, correlation values were never high and large differences in the correlation values at larger scales between natural or exotic forest and semi-natural pastures were lacking. Thus, except for the unfavourable effect of intensively managed pastures at all scales for native species, all other habitat types generated similar effects at large scales. Exotic forests seem not only to promote population connection of native species, but also to favour local populations' demographic increase. Our results demonstrate that the species compositions of both types of forest were not statistically different when native species were considered, highlighting the role of exotic forests as a refuge for autochthonous fauna. Even several endemic species have persisted only in exotic forests, e.g., species of the genus Tarphius (Coleoptera, Zopheridae) that seem to be adapted only to low altitudes, have been collected and persist in forests dominated by Acacia, Cryptomeria and Eucalyptus trees on the islands of Terceira, S. Jorge and Flores (Borges, 1991; Amorim, 2005). This important refuge role of planted forests has been emphasized on several occasions (Berndt et al., 2008; Bhagwat et al., 2008; Brockerhoff et al., 2008; Pawson et al., 2008).

Some endemic species are very abundant in pastures, namely the beetle Heteroderes azoricus (Elateridae) and the wolf-spider Pardosa acoreensis (Lycosidae). Both are habitat generalists and have been able to adapt to non-natural habitats. Very few endemic species are able to inhabit both semi-natural and intensively managed pastures, but surprisingly, those two species are able to sustain populations with similar or even higher abundances than those that inhabit natural forests. Their abundance in pastures is the sole explanatory factor for the almost inexistence of significant correlations when habitats are compared by their absolute abundance of endemics. Notably, population density is generally difficult to predict by using habitat variables (Johnson and Seip, 2008). In this study, correlations between endemic species abundance and habitat area were always low both at local and regional scales. This observation illustrates the difficulty of predicting variation in abundance without considering other variables, such as biotic interactions and facilitation processes (see also Borges et al., 2006). For example, fragmentation and edge effects can disrupt the biotic interactions existing in natural habitat types, promoting the occurrence of crowding (see Debinski and Holt, 2000).

A completely opposite pattern could be found for introduced species. Except for intensively managed pastures (favourable habitat), all remaining habitat types seemed to act as insulators for the local species richness and abundance of introduced species, following an opposite pattern to the one observed for endemics (see also Borges et al., in press). The local species richness of introduced species was negatively affected by the increase in area of natural forests (unfavourable habitat), both at local and regional scales. Exotic forests and semi-natural pastures were negatively correlated with richness of introduced species at large scales. As predicted by the model of Barlow and Kean (2004), due to metapopulation dynamics the local abundance of invasive species increases with the abundance of the appropriate habitat in the surrounding landscape.

\section{Conclusion}

Our results suggest that intensively managed pastures behave as a "sea matrix" (sensu Driscoll, 2005) or isolation factor for most of the Azorean arthropod endemic species. Thus, with the purpose of improving conditions necessary for the spreading of native and endemic species, intensively managed pastures should be replaced by semi-natural pastures, and most preferably, the increase of tree and shrub vegetation cover should be strongly encouraged. Grassland restoration is a complex issue (Pywell et al., 2007) and much evidence suggests that it is difficult, if not impossible, to re-establish the natural ancestral condition (Hobbs et al., 2006; Whittingham, 2007). However, it has been observed multiple times in the Azores that when grazing intensity decreases, the semi-natural pastures are easily invaded by the endemic shrub Erica azorica. This plant creates the conditions for the establishment of other natural forest species, thus representing the initial vegetation succession towards a true Laurisilva forest (Elias and Dias, 2009). To increase the success of these restoration designs, one needs to take into account not only the appropriate scale for conservation actions, but also the surrounding land-use (see Perfecto and Vandermeer, 2002; Umetsu et al., 2008).

This study highlights the importance of adequate standardized spatial data to study the occurrence and habitat requirements of insects and spiders on islands. The conservation of rare endemic species restricted to native habitats under pressure from a humanmodified matrix constitutes a challenge for the current and future generations of conservation managers.

\section{Acknowledgements}

Many thanks go to Isabel R. Amorim for her most useful comments and extensive English editing. PC and SA were supported by grants from Direcção Regional da Ciência e Tecnologia dos Açores (M112/F/014/2007 and M311/1009A/2005 respectively). FD and CG were supported by grants from Fundação para a Ciência e Tecnologia (SFRH/BD/13197/2003 and SFRH/BD/11049/2002 respectively). Funding for fieldwork was provided by Direcção Regional dos Recursos Florestais (Secretaria Regional da Agricultura e Pescas) through the project "Reservas Florestais dos Açores: Cartografia e Inventariação dos Artrópodes Endémicos dos Açores" (PROJ. 17.01-080203). We are also grateful for the financial support of the Spanish Ministry of Education and Science (project CGL 2006-10196).

\section{Appendix. Supplementary data}

Supplementary data associated with this article can be found, in the online version, at doi:10.1016/j.actao.2009.05.005

\section{References}

Amorim, I.R., 2005. Colonization and diversification on oceanic islands: forest Tarphius and cave-dwelling Trechus beetles of the Azores, Ph.D. dissertation, University of California.

Barlow, N.D., Kean, J.M., 2004. Resource abundance and invasiveness: a simple model. Biol. Invasions 6, 261-268.

Batáry, P., Báldi, A., Szél, G., Podlussány, A., Rozner, I., Erdős, S., 2007. Responses of grassland specialist and generalist beetles to management and landscape complexity. Divers. Dist. 13, 196-202. 
Berndt, L.A., Brockerhoff, E.G., Jactel, H., 2008. Relevance of exotic pine plantations as a surrogate habitat for ground beetles (Carabidae) where native forest is rare. Biodivers. Conserv. 17, 1171-1185.

Bhagwat, S.A., Willis, K.J., Birks, H.J.B., Whittaker, R.J., 2008. Agroforestry: a refuge for tropical biodiversity? Trends Ecol. Evol. 23, 261-267.

Borges, P.A.V., 1991. Two new species of Tarphius Erichson, 1848 (Coleoptera, Colydiidae) from the Azores. Bocagiana 143, 1-11.

Borges, P.A.V., Brown, V.K., 2004. Arthropod community structure in pastures of an island archipelago (Azores): looking for local-regional species richness patterns at small-scales. Bull. Entomol. Res. 94, 111-121.

Borges, P.A.V., Aguiar, C., Amaral, J., Amorim, I.R., André, G., Arraiol, A., Baz, A. Dinis, F., Enghoff, H., Gaspar, C., Ilharco, F., Mahnert, V., Melo, C., Pereira, F. Quartau, J.A., Ribeiro, S., Ribes, J., Serrano, A.R.M., Sousa, A.B., Strassen, R.Z. Vieira, L., Vieira, V., Vitorino, A., Wunderlich, J., 2005. Ranking protected areas in the Azores using standardized sampling of soil epigean arthropods. Biodivers. Conserv. 14, 2029-2060.

Borges, P.A.V., Lobo, J.M., Azevedo, E.B., Gaspar, C., Melo, C., Nunes, L.V., 2006 Invasibility and species richness of island endemic arthropods: a general mode of endemic vs. exotic species. J. Biogeo. 33, 169-187.

Borges, P.A.V., Ugland, K.I., Dinis, F.O., Gaspar, C. Insect and spider rarity in an oceanic island (Terceira, Azores): true rare and pseudo-rare species. In: Fattorini, S. (Ed.), Insect Ecology and Conservation, Research Signpost, in press.

Boyce, M.S., 2006. Scale for resource selection functions. Divers. Dist. 12, 269-276.

Brockerhoff, E.G., Jactel, H., Parrotta, J.A., Quine, C.P., Sayer, J., 2008. Plantation forests and biodiversity: oxymoron or opportunity? Biodivers. Conserv. 17, 925-951.

Cardoso, P., Borges, P.A.V., Gaspar, C., 2007. Biotic integrity of the arthropod communities in the natural forests of Azores. Biodivers. Conserv. 16, 2883-2901.

Cardoso, P., Gaspar, C., Pereira, L.C., Silva, I., Henriques, S.S., Silva, R.R., Sousa, P. 2008a. Assessing spider species richness and composition in Mediterranean cork oak forests. Acta Oecol. 33, 114-127.

Cardoso, P., Scharff, N., Gaspar, C., Henriques, S.S., Carvalho, R., Castro, P.H. Schmidt, J.B., Silva, I., Szüts, T., Castro, A., Crespo, L.C., 2008b. Rapid biodiversity assessment of spiders (Araneae) using semi-quantitative sampling: a case study in a Mediterranean forest. Insect Conserv. Divers. 1, 71-84.

Chao, A., 1984. Non-parametric estimation of the number of classes in a population. Scand. J. Stat. 11, 265-270.

Chust, G., Pretus, J.L., Ducrot, D., Ventura, D., 2004. Scale dependency of insect assemblages in response to landscape pattern. Landscape Ecol. 19, 41-57.

Clark Labs, 2004. Idrisi Kilimanjaro 14.02 Worcester, MA, USA.

Clarke, K.R., Gorley, R.N., 2001. PRIMER v5: user manual/tutorial, PRIMER-E, Plymouth UK.

Clarke, K.R., Warwick, R.M., 2001. Change in Marine Communities: an Approach to Statistical Analysis and Interpretation, second ed. PRIMER-E, Plymouth, UK.

Clough, Y., Kruess, A., Kleijn, D., Tscharntke, T., 2005. Spider diversity in cereal fields: comparing factors at local, landscape and regional scales. J. Biogeo. 32 2007-2014.

Damschen, E.I., Haddad, N.M., Orrock, J.L., Tewksbury, J.J., Levey, D.J., 2006. Corridors increase plant species richness at large scales. Science 3131, 1284-1286.

Debinski, D.M., Holt, R.D., 2000. A survey and overview of habitat fragmentation experiments. Conserv. Biol. 14, 342-355.

Didham, R.K., Hammond, P.M., Lawton, J.H., Eggleton, P., Stork, N.E., 1998. Beetle species responses to tropical forest fragmentation. Ecol. Monogr. 68, 295-323.

Didham, R.K., Tylianakis, J.M., Gemmell, N.J., Rand, T.A., Ewers, R.M., 2007. Interactive effects of habitat modification and species invasion on native species decline. Trends Ecol. Evol. 22, 489-496.

Driscoll, D.A., 2005. Is the matrix a sea? Habitat specificity in naturally fragmented landscape. Ecol. Entomol. 30, 8-16.

Driscoll, D.A., 2008. The frequency of metapopulations, metacommunities and nestedness in a fragmented landscape. Oikos 117, 297-309.

Dungan, J.L., Perry, J.N., Dale, M.R.T., Legendre, P., Citron-Pousty, S., Fortin, M.J. Jakomulska, A., Mirirti, M., Rosenberg, M.S., 2002. A balanced view of scale in spatial statistical analysis. Ecography 25, 626-640.

Elias, R.B., Dias, E., 2009. Gap dynamics and regeneration strategies in JuniperusLaurus forests of the Azores Islands. Plant. Ecol. 200, 179-189.

Ewers, R.M., Didham, R.K., 2008. Pervasive impact of large-scale edge effects on a beetle community. Proc. Natl. Acad. Sci. 105, 5426-5429.

Fischer, J., Lindenmayer, D.B., 2007. Landscape modification and habitat fragmentation: a synthesis. Global Ecol. Biogeo. 16, 265-280.

Gaucherel, C., Burel, F., Baudry, J., 2007. Multiscale and surface pattern analysis of the effect of landscape pattern on carabid beetles distribution. Ecol. Ind. 7, 598-609.

González-Mejias, A., Gómez, J.M., Sánchez-Piñero, F., 2007. Diversity-habitat heterogeneity relationship at different spatial and temporal scales. Ecography 30, 31-41.

Gotelli, N.J., Colwell, R.K., 2001. Quantifying biodiversity: procedures and pitfalls in the measurement and comparison of species richness. Ecol. Lett. 4, 379-391.

Hanski, I, 1999. Metapopulation Ecology Oxford University Press, Oxford, UK

He, F., Gaston, K.J., Connor, E.F., Srivastava, D.S., 2005. The local-regional relationship: immigration, extinction and scale. Ecology 86, 360-365.

Heleno, R., Ceia, R.S., Ramos, J.A., Memmott, J., 2009. Effects of alien plants on insect abundance and biomass: a food-web approach. Conserv. Biol. 23, 410-419.

Hendrickx, F., Maelfait, J.-P., Van Wingerden, W., Schweiger, O., Speelmans, M., Aviron, S., Augenstein, I., Billeter, R., Bailey, D., Bukacek, R., Burel, F., Diekötter, T.
Dirksen, J., Herzog, F., Liira, J., Roubalova, M., Vandomme, V., Bugter, R., 2007. How landscape structure, land-use intensity and habitat diversity affect components of total arthropod diversity in agricultural landscapes. J. Appl. Ecol. 44, 340-351.

Hobbs, R.J., Arico, S., Aronson, J., Baron, J.S., Bridgewater, P., Cramer, V.A., Epstein, P.R. Ewel, JJ, Klink, C.A, Lugo, A.E, Norton, D., Ojima, D. Richardson, D.M., Sanderson, E.W., Valladares, F., Vilà, M., Zamora, R., Zobel, M., 2006. Novel ecosystems: theoretical and management aspects of the new ecological world order. Global Ecol. Biogeo. 15, 1-7.

Hoekstra, J.M., Boucher, T.M., Ricketts, T.H., Roberts, C., 2005. Confronting a biome crisis: global disparities of habitat loss and protection. Ecol. Lett. 8, 23-29.

Holland, J.D., Bert, D.G., Fahrig, L., 2004. Determining the spatial scale of species' response to habitat. BioScience 54, 227-233.

Johnson, C.J., Seip, D.R., 2008. Relationships between resource selection, distribution, and abundance: a test with implications to theory and conservation. Pop Ecol. 50, 145-157.

Leibold, M.A., Holyoak, M., Mouquet, N., Amarasekare, P., Chase, J.M., Hoopes, M.F., Holt, R.D., Shurin, J.B., Law, R., Tilman, D., 2004. The metacommunity concept: a framework for multi-scale community ecology. Ecol. Lett. 7, 601-613.

Malanson, G.P., Cramer, B.E., 1999. Landscape heterogeneity, connectivity, and critical landscapes for conservation. Divers. Dist. 5, 27-39.

Olden, J.D., 2006. Biotic homogenization: a new research agenda for conservation biogeography. J. Biogeo. 33, 2027-2039.

Parker, M., Nally, R.M., 2002. Habitat loss and the habitat fragmentation threshold: an experimental evaluation of impacts on richness and total abundances using grassland invertebrates. Biol. Conserv. 105, 217-229.

Pawson, S.M., Brockerhoff, E.G., Meenken, E.D., Didham, R.K., 2008. Non-native plantation forests as alternative habitat for native forest beetles in a heavily modified landscape. Biodivers. Conserv. 17, 1127-1148.

Pearman, P.B., 2002. The scale of community structure: habitat variation and avian guilds in tropical forest understory. Ecol. Monogr. 72, 19-39.

Perfecto, I., Vandermeer, J., 2002. Quality of agroecological matrix in a tropical montane landscape: ants in coffee plantations in Southern Mexico. Conserv. Biol. 16, 174-182.

Pither, J., Aarssen, L.W., 2005. The evolutionary species pool hypothesis and patterns of freshwater diatom diversity along a pH gradient. J. Biogeo. 32, 503-513.

Pywell, R.F., Bullock, J.M., Tallowin, J.B., Walker, K.J., Warman, E.A., Masters, G., 2007. Enhancing diversity of species-poor grasslands: an experimental assessment of multiple constraints. J. Appl. Ecol. 44, 81-94.

Rahbek, C., 2005. The role of spatial scale and the perception of large-scale speciesrichness patterns. Ecol. Lett. 8, 224-239.

Resetarits, W.J., 2005. Habitat selection behaviour links local and regional scales in aquatic systems. Ecol. Lett. 8, 480-486.

Ricketts, T.H., 2001. The matrix matters: effective isolation in fragmented landscapes. Am. Nat. 158, 87-99.

Ricklefs, R.E., 1987. Community diversity: relative roles of local and regional processes. Science 235, 167-171.

Ricklefs, R.E., 2008. Desintegration of the ecological community. Am. Nat. 172, 741-750.

Schmidt, M.H., Thies, C., Nentwig, W., Tscharntke, T., 2008. Contrasting responses of arable spiders to the landscape matrix at different spatial scales. J. Biogeo. 35, $157-166$

Silva, L., Smith, C.W., 2004. A characterization of the non-indigenous flora of the Azores archipelago. Biol. Inv. 6, 193-204.

Steffan-Dewenter, I., Münzenberg, U., Burger, C., Thies, C., Tscharntke, T., 2002. Scale-dependent effects of landscape context on three pollinator guilds. Ecology 83, 1421-1432.

Stephens, D.W., Krebs, J.R., 1986. Foraging Theory. Princeton University Press, Chichester, Sussex, UK

Thomas, C.D., Kunin, W.E., 1999. The spatial structure of populations. J. Anim. Ecol. 68, 647-657.

Trani, G.M.K., 2002. The influence of spatial scale on landscape pattern description and wildlife habitat assessment. In: Scott, J.M., Heglund, P.J., Morrison, M.A., Haufler, J.B., Raphael, M.G., Wall, W.A., Samson, F.B. (Eds.) Predicting Species Occurrences: Issues of Accuracy and Scale. Island Press, Washington, pp. 141-155.

Turner, W.R., Tjørve, E., 2005. Scale-dependence in species-area relationships. Ecography 28, 721-730.

Turquin, M.-J., 1973. Une biocenose cavernicole originale pour le Bugey: Le puits de Rappe. Commptes Rendus 96e Congresse Naturel Sociétès Savantes, Toulouse 1971, Sciences 3, pp. 235-256.

Umetsu, F., Metzger, P., Pardini, R., 2008. Importance of estimating matrix quality for modeling species distribution in complex tropical landscapes: a test with Atlantic forest small mammals. Ecography 31, 359-370.

Whittaker, R.J., Willis, K.J., Field, R., 2001. Scale and species richness: towards a general, hierarchical theory of species richness. J. Biogeo. 28, 453-470.

Whittingham, M.J., 2007. Will agri-environment schemes deliver substantial biodiversity gain, and if not why not? J. Appl. Ecol. 44, 1-5.

Wiens, J.A., 1989. Spatial scaling in ecology. Funct. Ecol. 3, 385-397.

Williamson, M., 1996. Biological Invasions. Chapman \& Hall, London.

Woodcock, B.A., Potts, S.G., Pilgrim, E., Ramsay, A.J., Tscheulin, T., Parkinson, A., Smith, R.E.N., Gundrey, A.L., Brown, V.K., Tallowin, J.R., 2007. The potential of grass field margin management for enhancing beetle diversity in intensive livestock farms. J. Appl. Ecol. 44, 60-69. 